\title{
Leading Change: Adaption of Information Security in University Announcement System
}

\author{
Al-Shawabkeh M. ${ }^{1}$, Xichun $\mathrm{Li}^{2}$, Mohamed Sullabi ${ }^{3}$ \\ 1. National Defense University of Malaysia \\ 2. Guangxi Normal University for Nationalities, Chongzuo City, Guangxi Province, China \\ 3. Libyan Academy, Misurata, Libya \\ mahmoud.alshawabkeh@gmail.com,291495244@qq.com, sullabi@lam.edu.ly
}

\begin{abstract}
Keywords: leading change; information security; awareness; leadership; adaption; Success
\end{abstract}
\begin{abstract}
Many important reasons influence the organization needs of adoption change as strategic decision. Among this reasons the internal and external forces that inforce organization to find new ways to improve performance on both organizational and individual levels. By applying change, the organization need an effective leadership management. Organization effective change management understood by referring to John Kotter book 'Leading Change'. In his book, Kotter proposed an 8-Stage change model that, defines 8 process to successfully implementation of change. In this paper, Kotter's model extend with information security stage for answering the question "To what extent does leading change management model improve university announcement system performance?".
\end{abstract}

\section{Introduction}

In this paper, Kotter's 8-Step model extend with one more stage, the information security stage. Kotter steps focus on de-freezing process in first 4 stages. Change team individuals will recognize the importance of change during de-freezing process. Stages from 5 to 7 do the change. Then stage 8 will re-freeze the organization with new change $[1,2]$. The new proposed stage number 9 is information security awareness. All steps should implemented in order without skipping any single stage to avoid system failure. The structure of the paper organized as follows: Section 2 presents university announcement system, history, currents state, and plan. Section 3 present literature review, then section 4 explain the proposed model. Finally, Section 5 concludes the paper and points out further work.

\section{University Announcement System History, Current State, and Future Plan}

National Defense University of Malaysia (NDUM) focus to become the knowledge hub for defense technology in Malaysia and South East Asia. The university graduates have successfully inducted and now suit as full officers in the Malaysian Army, Royal Malaysian Navy, Royal Malaysian Air Force, also in other Government Sectors and Non-Government Sectors.

Current state shows Announcement System in the university is not effective. When it is time to inform university students or staff about news or events there is some ambiguity and uncertainty cause to miss understanding. Students and staff keep complains that they not been alert effectively to what is happening in the university.

The current announcements, the news and events are post on either a simple website or social network applications, mainly Facebook and Tweeter. Videos uploaded on YouTube because of video large size. By July 2016, on Facebook page (facebook.com/upnm2u) there are total of 3640 page likes only. On Tweeter (twitter.com/upnm), there are 134 tweets, 9 following, and 533 followers.

On YouTube (youtube.com/user/upnm2u), there are 97 subscribers for only 24 Uploads. There is no statistics shows number of hits on announcements made on website (http://www.upnm.edu.my/en/).

To know the reason why students and staff not use effectively the official university announcement channels, basic Investigations done. Investigation results shows that students and staff 
have several untrusted, unsecure, and unofficial social networks channels that are popular and visited regularly because of the interesting posts, buy and sale, and no worry to comment and share without the boss knows what is happening. Administrators of this social networks channels are either university students and staff who does not understand the consequences on what they are doing, or ordinary civilians likes to admin the social networks for fun, or unknown person with unknown agenda behind this. This clearly shows the leak of effectiveness and security in the current university announcement system. Several incidents happen during last few years. Some of them were a fake announcements telling fake news, or news altered purposely. Others were organized attacks against university stability.

University plan to develop and implement an Announcement System. This system is a computer program to be use on university staff and students' desktops, Laptops, and mobile devices. The new system is in implementation stage, and will be available for download from university website, Google Play, and Apple's App Store. During the change process from current stage to new stage, expected to have success and failure. The proposed model aims to explain how to manage and lead the change process.

\section{Literature Review}

3.1 The Level 5 Leadership Model. Jim Collins in his bestselling book, "From Good to Great", identified the characteristics and success of level 5 leaders who blends extreme personal humility with intense professional will [3]. Levels are position, relationship, results, develop, and respect levels.

3.2 Situational Leadership Model. Paul Hersey and Ken Blanchard book "The Situation Leader", explained the situational leadership model [4, 5]. Different level of leadership are necessary depending on the situation. The model can implemented through three steps. 1) Identify the most important tasks or priorities. 2) Consider the readiness level of staff by analyzing the staff's ability and willingness to do the task. 3) Select and apply the appropriate situational leadership style to fit the given situation. The appropriate situational leadership are directing, coaching, supporting, and delegating styles.

\section{Proposed Model}

Stage 1: Create Urgency. Fig. 1 shows proposed model stages. Stage 1 is to develop a sense of urgency around the need for change to ensure the change will happen. Should not do that only by showing statistics of university announcement system usage. However, open a convincing dialog with students and staff about what is really happening. To build urgency, students and staff must start talking about the change we plan to do. Steps of doing that can be through:

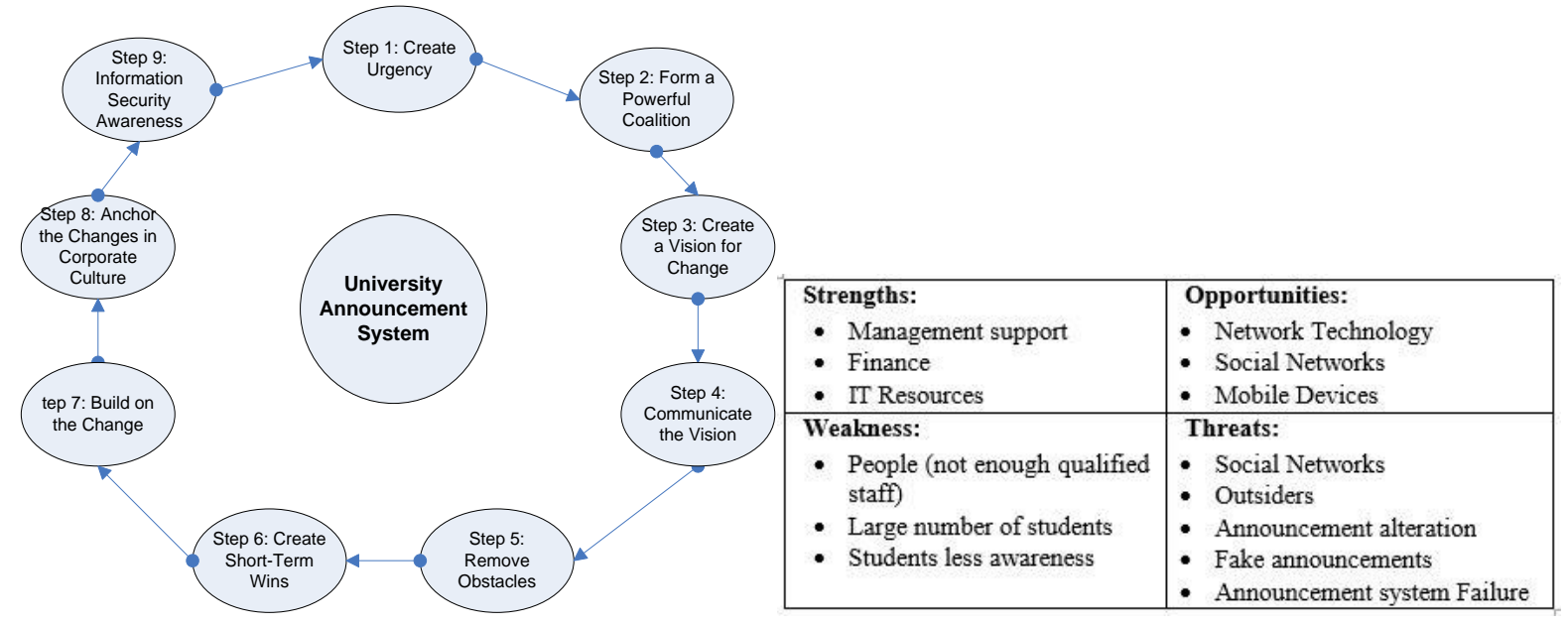




\section{- Start honest discussions}

Get students and staff talking and thinking about importance and usage of announcement system. That could initiated by a short video message from the university rector.

\section{- Identify potential threats}

Let students and staff know what the risk behind not using the system effectively. Some example of risks are, if new system not implemented effectively, students and staff will not be able to trust any announcement received about university news and events. Other risks comes from outsiders who purposely post announcements on unofficial social networks channels to create uncertainty in university environment.

\section{- develop scenarios}

o Showing students and staff plans of what could happen in the future. Tell them they will be required to have an app installed on their mobile devices and/or laptops.

$\circ$ Inform them they will require reading and accepting information security policy when it is ready and before using the new system.

- Create change objectives, AWOT Analysis, and Fishbone Diagram

Objectives of this changing to new university announcement system is:

- Identify the need of change in Announcement System of National Defence University of Malaysia (NDUM).

- Define change models, then select and apply best change strategy suitable for the university announcement system.

- Use the available tools and techniques for generating change ideas, and make decision on how to implement the proposed change.

- Propose and implement a change plan.

- Lead the change and recognise change resistance then motivate others to change.

- Evaluate the change using change analysis techniques, and prepare for future change.

To determine the university's current ability to apply the change process successfully, the SWOT (strength, weaknesses, opportunities, threats) analysis is best way to use. Proposed National Defense University of Malaysia SWOT analysis shown in Fig. 2. Also called Cause and Effect Diagram, or Ishikawa Diagram. This diagram used to identify possible causes for a problem. Fig. 3 shows fishbone diagram for the university announcement system.

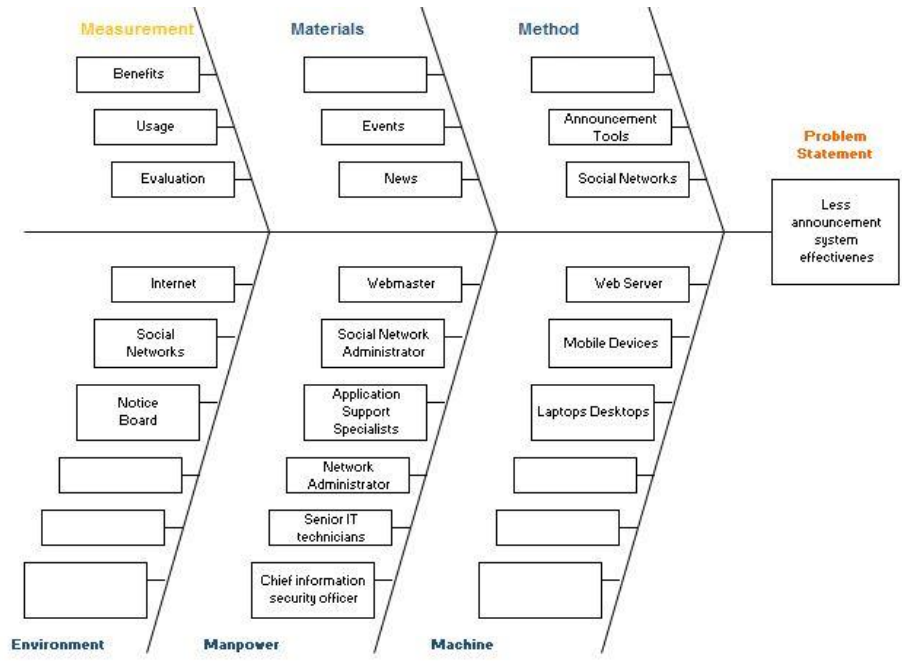

Figure 3 Fishbone Diagram

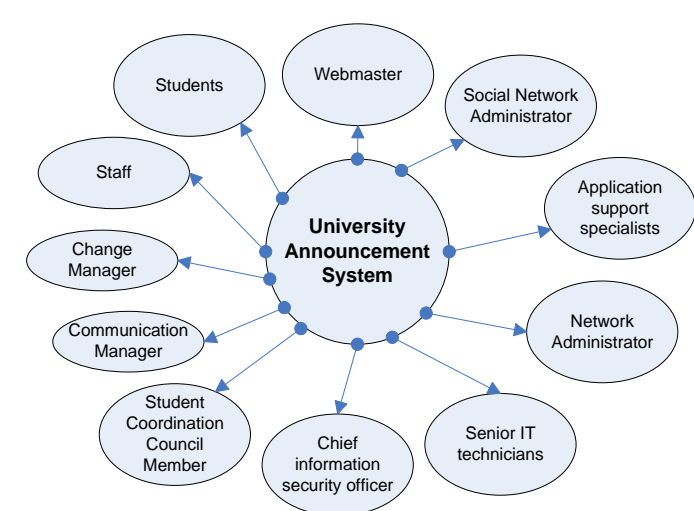

Figure 4. Stakeholder Map

Stage 2: Form a Powerful Coalition. To lead change in university announcement system, a team created from university influential people whose power comes from a variety of sources, including job title, status, expertise, and political importance. Situational leadership model used for selecting 
change team. Both technical and management staff are involved. The team members are Change Manager, Communication Manager, Chief information security officer, Senior IT technicians, Network Administrators, Application support specialists, Social Network Administrator, Webmaster, and Student Coordination Council Member. Any person effected by change is a stack holder. No matter the effect beneficial or damaging to him. To predict and explore change implication on stakeholders through stockholder analysis procedure. First step in stakeholder analysis is to develop the stakeholder map. Fig. 4 shows stakeholder map for university announcement system.

From stakeholder map, we can anticipate stakeholder's behavior and perception in relation to the proposed change.

Next step is to create the analysis table. In the analysis table, we can identify disadvantages of stakeholders from the change, identify stakeholder's response, and identify the recommended action to change management team. Table 1 . Shows stakeholders analysis table for university announcement system.

\begin{tabular}{|l|l|l|l|l|}
\hline Stakeholder & Benefits & Disadvantages & $\begin{array}{l}\text { Anticipation } \\
\text { Response }\end{array}$ & $\begin{array}{l}\text { Recommended } \\
\text { Action }\end{array}$ \\
\hline Student & High & Low & High & Use after awareness \\
\hline Staff & High & Low & High & Use after awareness \\
\hline Chief information security officer & Low & Low & Medium & Leadership change \\
\hline Senior IT technicians & Medium & Medium & Medium & $\begin{array}{l}\text { Monitoring the } \\
\text { system }\end{array}$ \\
\hline Network Administrators & Medium & Medium & Medium & $\begin{array}{l}\text { Monitoring the } \\
\text { system }\end{array}$ \\
\hline Application support specialists & Medium & Medium & Medium & $\begin{array}{l}\text { Developing the } \\
\text { system }\end{array}$ \\
\hline Social Network Administrator & Medium & Medium & High & Post announcements \\
\hline Webmaster & Medium & Medium & High & Post announcements \\
\hline $\begin{array}{l}\text { Student Coordination Council } \\
\text { Member }\end{array}$ & High & Low & High & Use after awareness \\
\hline Change Manager & Low & Low & Medium & Leadership change \\
\hline Communication Manager & Low & Low & Medium & Leadership change \\
\hline
\end{tabular}

Table 1: Stakeholders Analysis Table

Stage 3: Create a Vision for Change. Good and clear vision is necessary, to have a chance of achieving successful change. According to Eadie and Edward, "Vision assist employees in gaining a sense of identification with the organization, which in turn motivates them to achieve personal and organizational objectives" [6]. Conversely. A lack of vision is associated with organizational decline and failure as Beaver argues, "Unless organizations have clear vision about how they are going to be distinctly different and unique in adding and satisfying their customers, then they are likely to be corporate failure statistics of tomorrow" [7]. The proposed vision for the university announcement system: "To be a Blue Ocean Leading Institute with Best Announcement System in South East Asia Region".

Stage 4: Communicate the Vision. Communication has an important role in the management of change. During communication we focus on 'what, when, who, and how' of the communicating among change team members. Communication during change process is important because it's related to making vision easier, improving feedback, and providing social support [8]. At university announcement system, the recommendation to change team to not talk about vision only in meetings. Instead, they are required to talk about vision every chance they get. Lead by example is the method to be use by team leader when communicating the vision. He will keep referring to vision all the time, the team members will keep remember the vision each time they perform process to daily job.

Stage 5: Remove Obstacles. The eight common reasons change failures are 1) having complexity, 2) Not having a substantial coalition, 3) Not having a clear vision, 4) Not clearly communicate the vision, 5) Permitting roadblocks against that vision, 6) Not planning for short term results and not realizing them, 7) Celebrating victory too soon, 8) Not to anchor changes in corporate culture [2]. Implementing change will lead to several challenges. After reach the point of all change team 
members wants to get busy and achieve the benefits that been promoting. Maybe someone resisting the change. Removing obstacles can empower the team members and help the change move forward. To remove obstacles, team leader should recognize and reward team members for making change happen, Identify members who are resisting the change, and help them see what's needed, finally, take action to quickly remove barriers (human or otherwise). Table 2 shows the chick list needed by university change leadership.

\begin{tabular}{|l|l|l|}
\hline Reasons for Change Failures & Stakeholder & Quick Action \\
\hline having complexity & Students & Training on how to use the system \\
\hline Not having a substantial coalition & Change Team Leader & Leadership training \\
\hline Not having a clear vision & Change Team & Lead by Example \\
\hline Not clearly communicate the vision & Change Team & Communication Skills Training \\
\hline Permitting roadblocks against that vision & Change Team & Awareness Programme \\
\hline $\begin{array}{l}\text { Not planning for short term results and not } \\
\text { realizing them }\end{array}$ & Change Team Leader & Motivation Skills Training \\
\hline $\begin{array}{l}\text { Celebrating victory too soon } \\
\text { Not to anchor changes in corporate } \\
\text { culture }\end{array}$ & $\begin{array}{l}\text { Change Team Leader \& Change } \\
\text { Team }\end{array}$ & Leadership Training \\
\hline
\end{tabular}

Table 2: Quick Action Chick List

Stage 6: Create Short-Term Wins. There is nothing motivates more than perception of success. To motivate change team, do appropriate celebration after short-term targets success stat delivered. Without this, critics and negative thinkers might hurt change progress. Table 3 shows some best quick wins celebrations.

\begin{tabular}{|l|l|}
\hline Target Stage & Rewards \\
\hline Sense of Urgency & In house lunch \\
\hline Define Objectives & Weekend invitation to movie \\
\hline Form a Change Team & In house lunch \\
\hline Vision Created & In house lunch \\
\hline Development of the software & Cash bonus \\
\hline $\begin{array}{l}\text { Finishing first group of information security awareness } \\
\text { programme }\end{array}$ & In house lunch \\
\hline Initial statistics that shows rising in usage & One month salary bonus \\
\hline Obstacles Removed & $10 \%$ salary bonus \\
\hline
\end{tabular}

Table 3: Short-Term Wins Rewards

Stage 7: Build on the Change. To reach $20 \%$ of university population using university announcement system is great. To reach $100 \%$ success, need to keep looking for continuous improvements. To keep university announcement system improve, change team should after every win, analyze what went right, and what needs improving. One approach to continuous, incremental improvement called kaizen. It originated in Japan and the word translates to mean change (kai) for the good (zen) [9]. A simple way to explain kaizen is, there is always room to make small improvements, and over time, all of these incremental changes add up, and make a significant positive impact on organization.

Stage 8: Anchor the Changes in University Culture. To make any change stick, it should become part of the core of university activities. Change team to do continuous efforts to ensure that the change seen in every aspect of the university announcement system. This will help give that change a solid place in university culture. The change team recommended keeping talking about the success by telling stories about the achievements. Make sure everyone to remember and recognize change coalition.

Stage 9: Information Security Awareness. The reason of promoting information security awareness is to ensure that security procedures are available to all announcement system users, especially, students and staff. With respect to information security awareness, both university students and staff need to have training to be able to do two basic actions: 1) Recognize when an incident occurs or what could case an incident to occur. 2) Know where to report the incident when 
the incident is happen [10]. The awareness training to students and staff to done in mass lectures or in groups during their free time. Emails, memos, intranet, and notice board used to post security awareness information. Furthermore, security policy created and delivered to all announcement system users to read, understand, and accept it.

\section{Conclusions}

The proposed change model help National Defense University of Malaysia to adapt new technology to improve announcement system effectiveness, as well as to adjust and succeed. The new change is ongoing process that involves constantly re-organizing the system from ground level to top levels. To implement the proposed model, firstly management to establish sense of urgency around the need for change. This step identify system potential threats, develop change scenarios, objectives, SWOT analysis, and Fishbone diagram. Step 2 establish change team base on situational leadership model. In step 3, vision and strategy created and shared with everyone to have the same goal. Step 4 communicate the vision and increase change team effectiveness by imposing motivation and training. Step 5 remove obstacles when having resistance to change, a plan of removing obstacles to change created including identifying obstacles and having the answer to all questions on difficulties of change implementation. Step 6 generate short-term win. Step 7 consolidate gains and produce more change and if possible. Continuous improvement proposed by using Kaizen method. Step 8 anchor new approached in the new culture. Finally, step 9 propose information security awareness. By that, the change success and improvement can happen. Nevertheless, moving to the future, there are limited options and choices. With major university activities, this require commitment from students, staff, change team, and university management.

\section{Acknowledgment}

This work supported by Guangxi Normal University for Nationalities grant (No.2012JGZ146), all support gratefully acknowledged.

\section{References}

[1] J. P. Kotter, Leading Change. Boston: Harvard Business School Press, 1996.

[2] Kotter and Cohen, The Heart Of Change. Boston: Harvard Business School Press, 2002.

[3] J. C. COLLINS, Good to great: why some companies make the leap ... and others don't. New York, NY: HarperBusiness, 2001.

[4] P. Hersey, The situational leader. New York, NY: Warner Books, 1985.

[5] P. a. B. Hersey, K. H., Management of Organizational Behavior: Utilizing Human Resources. New Jersey: Prentice Hall, 1977.

[6] D. Eadie and R. L. Edward, "Board Leadership by Design," Nonprofit World, vol. 11, pp. 12-15, 1993.

[7] G. Beaver, "The Significance of Strategic Vision, Mission and Values," Strategic Change, vol. 9, pp. 205-207, 2000.

[8] L. K. Lewis, ""Blindsided by the One" and "I Saw That One Coming": The relative Anticipation and Occurrence of Communication Problems and Other Problems in Implementers' Hindsight," Jornal of AppliedCommunication Research, vol. 28, pp. 44-67, 2000.

[9] M. Imai, Kaizen-The Key to Japanese Competetive Success. London The Kaizen Institute Ltd, 1986.

[10] T. Fitzgerald, Information security governance simplified: from the boardroom to the keyboard: CRC Press, 2011. 